8-1-2019

\title{
Enhancing respectful maternal care during labor and delivery
}

Breakthrough RESEARCH

Follow this and additional works at: https://knowledgecommons.popcouncil.org/departments_sbsr-rh

Part of the Health Communication Commons, and the Public Health Commons How does access to this work benefit you? Let us know!

\section{Recommended Citation}

Breakthrough RESEARCH. 2019. "Enhancing respectful maternal care during labor and delivery," Programmatic Research Brief. Washington, DC: Population Council. 


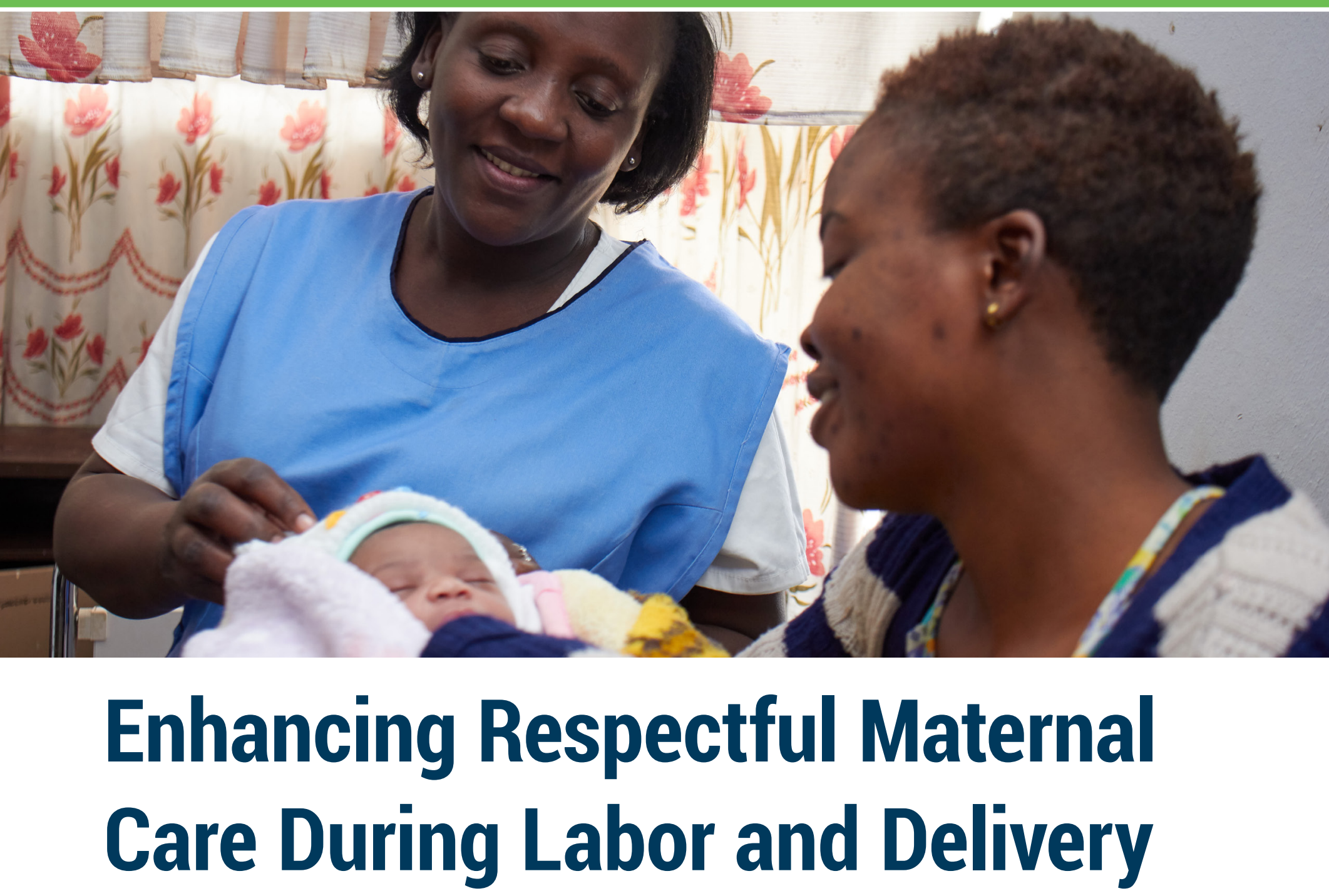

This brief informs national ministries of health, health systems stakeholders, implementing partners, and donors on innovative ways to improve women's experiences during labor and delivery. It describes how behavioral design led to new insights into why health care providers may not follow best practices in providing respectful maternal care (see Box). ideas42, in partnership with Safe Motherhood 360+ and the Chipata District Health Office in Zambia, under the Breakthrough RESEARCH project, used behavioral design to analyze contextual features and behavioral barriers to respectful maternal care in urban and rural health care settings. The insights from the process led to a set of simple, adaptable low-cost solutions to help providers follow best practice guidelines that were well received by providers and clients.

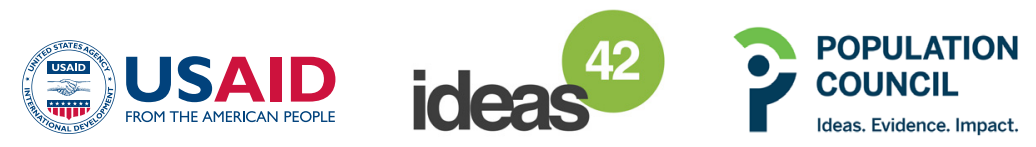

\section{KEY MESSAGES}

- Behavioral design offers new tools to improve the experience of care for women in labor and delivery.

- Behavioral design's participatory nature gives clients and providers a role to play in designing local health care solutions.

- The process and solutions in Zambia can be adapted and used to improve the experience of care in other contexts. 


\section{Step 2: Diagnose the context and drivers of the behavior}

The team generated a wide range of hypotheses to explain why providers may not be following best practices. They conducted onsite research to identify behavioral barriers to respectful care and the specific contextual features triggering those behaviors. The diagnosis revealed:

- Five behavioral barriers preventing providers from explicitly and consistently providing respectful care.

- Specific contextual features that drive these behavioral barriers that can be addressed with innovative solutions.

These barriers and drivers are shown in the Figure.

\section{Figure: Behavior Barriers to Respectful Care and Their Contextual Drivers}

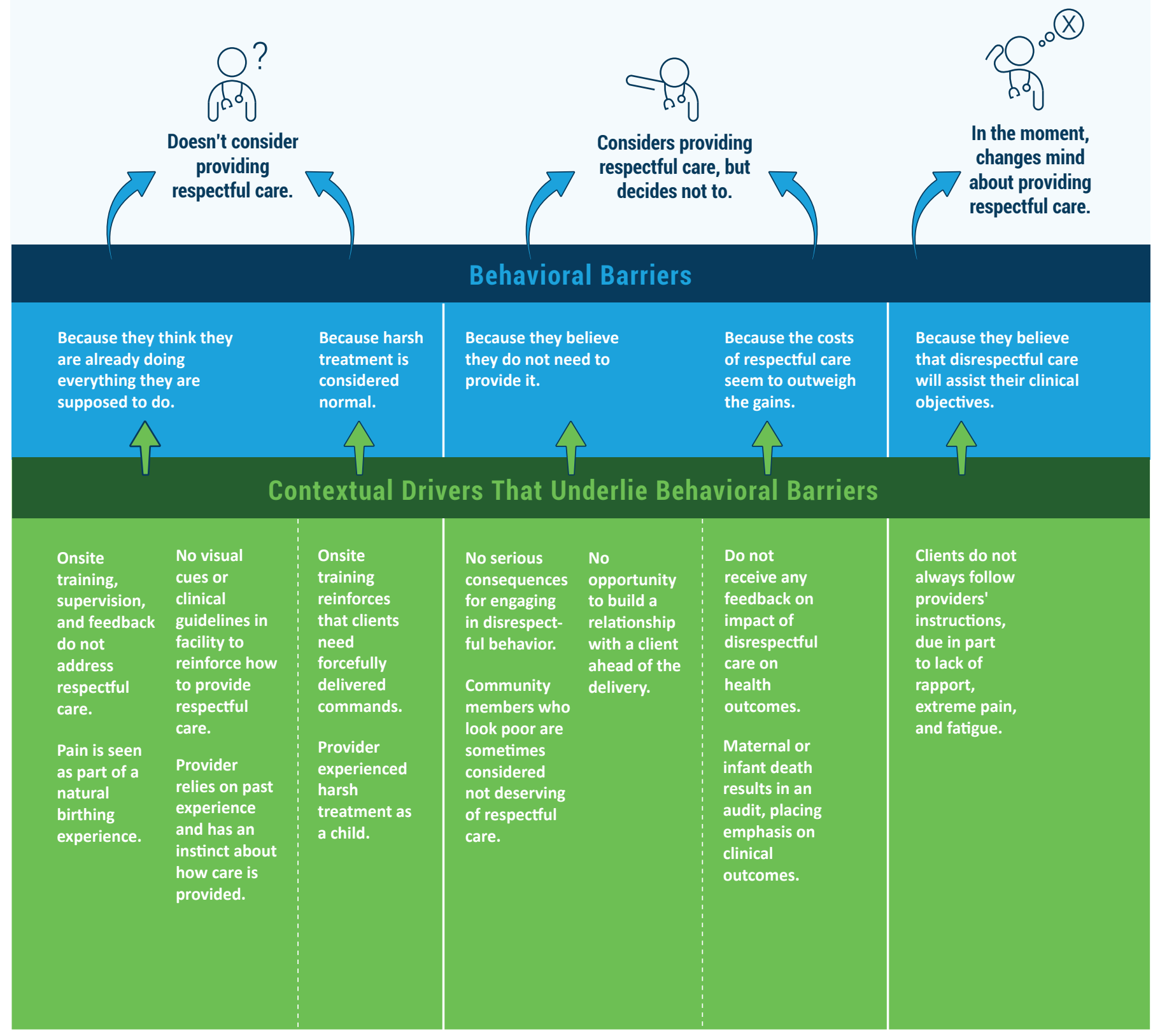




\section{Step 3: Design solutions to solve the problem}

The team generated many ideas to address the contextual features discovered during diagnosis. They developed prototypes of possible solutions and tested these with clients and providers. After two weeks of iterative testing and feedback, four low-cost, scalable prototypes were finalized. These new solutions, and the reactions to them from clients and providers, are described below:

1. Pain Management Toolkit, to incorporate the idea of pain management as part of routine client care, and to give reminders to providers to use pain management techniques regularly. This toolkit included:

Manual of pain management techniques framed as a clinical guide.

Display partograph that prompts providers to provide specific pain management techniques at different stages of labor. ${ }^{12}$

Pain management poster (shown below, as designed onsite, in local language) with mnemonic of techniques to cue providers to offer pain management.

"Hope Box" of photos, massage ball, and other objects for clients to look at while in labor, as distractions from pain or anxiety.

\section{BETTER}

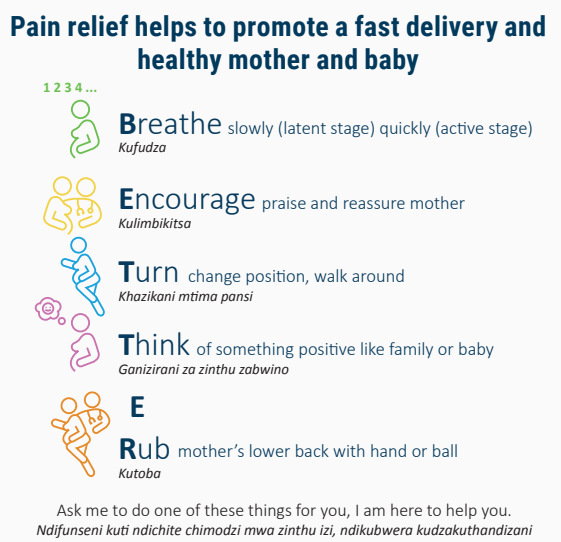

\section{Reactions From Clients and Providers to the Pain Management Toolkit:}

Clients reacted favorably to the techniques, especially the back massage. It was clear they were unaccustomed to receiving this kind of support from most providers.

Providers said that a poster in the room would be a helpful reminder to explain and provide pain relief to clients and that they were aware of several of the proposed pain management techniques, but did not typically provide them.

2. Provider-Client Promise, to clarify and set expectations for behavior on the side of both provider and client during admission, and reassure clients of the treatment they should receive. The tools included:

A large poster-size version of the Provider-Client Promise with large icons, as designed on site in local language.

A paper version that both provider and client read aloud and sign upon arrival to the labor room.

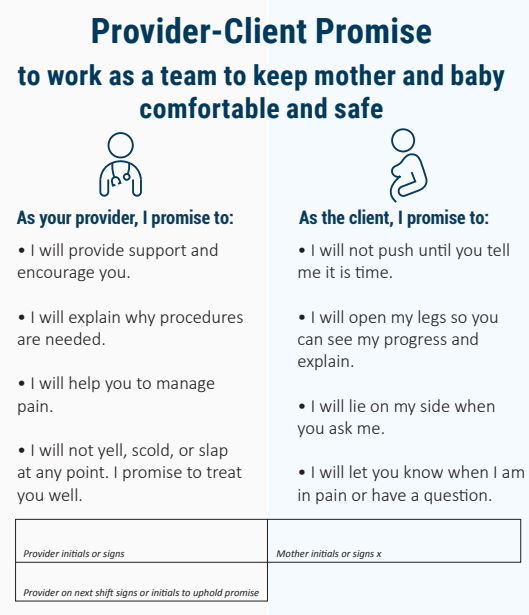

\section{Reactions from Clients and Providers to the Provider-Client Promise:}

Clients responded positively. After reading the promise, several clients mentioned past personal experiences of mistreatment. The promise gave them trust that this provider would not behave in that way.

Providers had mixed reactions. Some liked it, saying: "It will give reassurance to your patient; it will help them know that we are friends, that we are a team." But, some expressed hesitation with the word "promise," and had reservations about promising not to yell during labor. 
3. Feedback Box, to empower clients to share feedback on their experience at birth routinely and provide the means to assess clinic performance. The Feedback Box included:

A box located close to the labor and delivery room but out of sight of the providers, with three compartments marked with different satisfaction ratings.

A token for clients to "vote" on how she feels about her experience by dropping it into one of the slots in the box.

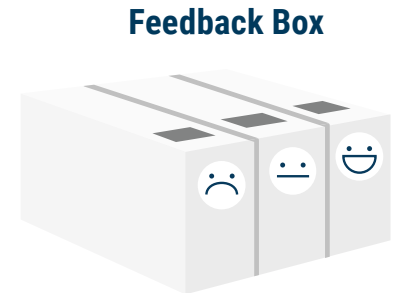

Reactions from Providers to the Feedback Box:

Providers reacted favorably, saying that it would help them to improve their work. Providers also shared how individual clinics could use the results during routine meetings to discuss ways to enhance clients' experience of care.

4. Reflection Workshop, to encourage provider reflection on client care and instill a commitment to change. This reflection workshop was not user-tested in Zambia, but a similar reflection meeting was held with clinical providers in one of the facilities. This workshop would be the channel to launch implementation of the other interventions and generate reflection on:

The current state of care in the facility.

Its impact on clients.

Sharing experiences of respectful care.

Given the successful results from two weeks of user testing, the local stakeholders including the Ministry of Health District Health Office, USAID/Zambia, and Safe Motherhood 360+ decided to move forward with implementation of the solutions in a few pilot facilities. The project team is developing simple operational guides and training materials to incorporate the solutions into the clinical mentorship program run by Safe Motherhood $360+$ and will seek to document lessons learned throughout the pilot.

\section{Applying Behavioral Design to Improve Health Programs}

The participatory nature of behavioral design offers stakeholders invested in quality improvement the opportunity to shape new solutions to positively influence provider behavior and improve the experience of care in ways that will be most effective for their settings. While the solutions were designed for respectful maternal care in Zambia, the solutions may be applicable to other contexts. The insights emerging from behavioral design about barriers to respectful maternal care may be pertinent to provider behavior change interventions in other health settings and contribute to a larger body of research focused on improving the experience of care for clients.

Behavioral design is a promising approach to transforming health care delivery, as its cutting-edge tools can shed new light on complex human behavior issues. It offers opportunities for clients, providers, and other stakeholders to co-create practical solutions for improved health care delivery. 


\section{References}

1 Bohren, M.A., et al. 2015. "The mistreatment of women during childbirth in health facilities globally: a mixed-methods systematic review," PLoS Medicine 12(6): e1001847.

2 Kruk, M.E., et al. 2009. "Bypassing primary care facilities for childbirth: a population-based study in rural Tanzania," Health Policy Plan 24(4):279-88

3 Mselle, L.T., et al. 2013. "Why give birth in health facility? Users' and providers' accounts of poor quality of birth care in Tanzania," BMC Health Services Research 13(1):174

4 Kujawski, Stephanie, et al. 2015. "Association between disrespect and abuse during childbirth and women's confidence in health facilities in Tanzania," Maternal and Child Health Journal 19(10) 2243-2250

5 Vogel J.P., et al. 2016. "Promoting respect and preventing mistreatment during childbirth," BJOG: An International Journal of Obstetrics \& Gynaecology 123:671-4.

6 Reis Veronica et al. 2012. Respectful Maternity Care: Country Experiences. Washington, DC: USAID, MCHIP.

7 World Health Organization (WHO). 2016. Standards for Improv ing Quality of Maternal and Newborn Care in Health Facilities. www.who.int/maternal_child_adolescent/documents/improv-ing-maternal-newborn-care-quality/en/.

8 WHO. 2018. WHO Recommendations on Intrapartum Care for a Positive Childbirth Experience. www.who.int/patientsafety/ implementation/checklists/childbirth/en/.

9 Van Lonkhuijzen, L., et al. 2010. "A systematic review of the effectiveness of training in emergency obstetric care in low-resource environments," BJOG: An International Journal of Obstetrics \& Gynaecology 117(7): 777-787.

10 Shakibazadeh, Elham et al. 2018. "Respectful care during child birth in health facilities globally: a qualitative evidence synthesis," BJOG: An International Journal of Obstetrics \& Gynaecology 125(8): 932-942

11 The complete behavioral design process includes 5 steps: (1) Define; (2) Diagnose; (3) Design; (4) Test; and (5) Scale. The process in Zambia included the first three steps. Full reports of the process and results in Zambia provide more details. https:// breakthroughactionandresearch.org/about/breakthrough-research/.

12 A partograph is a graphical record of the progress of labor and conditions of the mother and fetus, as documented by the provider

\section{Acknowledgments}

This programmatic research brief describes work led by ideas42 under Breakthrough RESEARCH in collaboration with the Chipata District Health Office in Zambia and SafeMotherhood 360+. The brief was developed by Population Reference Bureau (PRB). Please see the forthcoming technical reports for additional details: "Breakthrough RESEARCH Provider Behavior Change Literature Review 2018"; "Barriers to Provision of Respectful Maternal Care in Zambia"; and "Solutions for the Provision of Respectful Maternal Care."

\section{Suggested citation:}

Breakthrough RESEARCH. 2019. "Enhancing respectful maternal care during labor and delivery," Programmatic Research Brief. Washington, DC: Population Council.

\section{Photo credits:}

Cover Photo: Katyesi Media

Page 2: () 2000 Harvey Nelson, Courtesy of Photoshare

(c) 2019 The Population Council. All rights reserved.

\section{Feedback}

We'd love to hear your thoughts on this product and how it has helped you in your work. Send us your feedback!

breakthroughresearch@popcouncil.org

\section{Breakthrough RESEARCH, Population Council}

4301 Connecticut Ave., NW, Suite 280 | Washington, DC 20008 +12022379400 | breakthroughactionandresearch.org

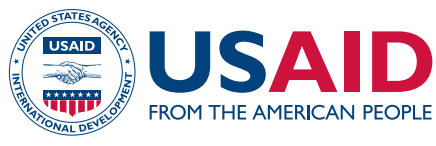

Breakthrough RESEARCH is made possible by the generous support of the American people through the United States Agency for International Development (USAID) under the terms of cooperative agreement no. AIDOAA-A-17-00018. The contents of this document are the sole responsibility of the Breakthrough RESEARCH and Population Council and do not necessarily reflect the views of USAID or the United States Government.
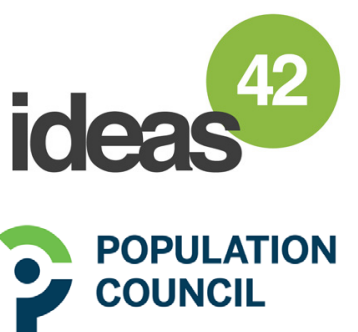

Ideas. Evidence. Impact.

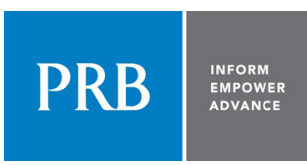

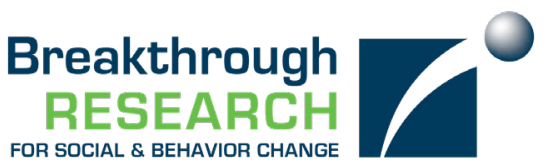

Breakthrough RESEARCH catalyzes social and behavior change (SBC) by conducting state-ofthe-art research and evaluation and promoting evidence-based solutions to improve health and development programs around the world. Breakthrough RESEARCH is a consortium led by the Population Council in partnership with Avenir Health, ideas42, Institute for Reproductive Health at Georgetown University, Population Reference Bureau, and Tulane University. 